\section{Comments on Highway Speeds}

\section{Communication}

\author{
K. A. Stonex, assistant engineer in charge, technical \\ liaison section, General Motors Corporation, War- \\ ren, Mich.
}

THE ARTICLE entitled "Highway Risks at Extreme Speeds," by Dr. Irwin D. J. Bross, in Public Health Reports, vol. 78, January 1963, appears to be an authoritative analysis of the cause of some highway fatal accidents and to offer equally authoritative solutions. However, the hypothesis is based on two premises which cannot be sustained, and the paper includes a characterization of highway accident types which can be justified only after the hypothesis is proved.

Because the hypothesis is not sustained and because it has already received some attention before the Conference on Passenger Car Design and Highway Safety, sponsored by the Association for the Aid of Crippled Children and Consumers Union, and before a legislative committee, it seems desirable to review it critically.

The first wrong premise appears in the discussion on page 29 relating to speed and lateral forces. According to the assumption, a typical middle-aged driver accustomed to driving at conservative speeds is, for the purposes of the analogy, now traveling at $80 \mathrm{mph}$. He makes a maneuver to avoid an obstacle on the road "and let us assume that he does not panic and that he follows his usual driving habits." By this we conclude that Dr. Bross means that the driver turns the steering wheel at his usual normal rate of rotation and therefore develops front wheel slip angles (1-5) at the same rate as if he had been traveling $40 \mathrm{mph}$.

Dr. Bross makes the assumption that simply because the speed is now $80 \mathrm{mph}$, high accelerative forces will come into being and that doubling the speed results in a fourfold increase in these forces. This is true only if the radius of curvature is the same in both cases. In the analogy used by Dr. Bross, the slip angle developed at any time would be the same as if the speed were $40 \mathrm{mph}$; this means that the force available to accelerate the car radially is the same as it would be at $40 \mathrm{mph}$, because the only lateral forces available to accelerate the car radially are those developed by the front tires operating at some slip angle (2-5). If we assume that the slip angle at some time is of the size to develop $0.2 \mathrm{~g}$ radial acceleration, the radius of curvature can be computed as shown in the following equations (6). At $40 \mathrm{mph}$ the radius is about 540 feet, and at $80 \mathrm{mph}$ it is about 2,150 feet. The radius is a function of the square of the speed, and the high $\mathrm{g}$ forces mentioned by Dr. Bross simply do not exist.

$$
\text { Centrifugal force, } \begin{aligned}
& F=\frac{W v^{2}}{g R} \\
& W=\text { weight } \\
& v=\text { speed, ft./sec. } \\
& g=\text { acceleration of gravity } \\
& R=\text { radius of curvature } \\
& \frac{F}{W}=e=\frac{V^{2}}{g R} \\
& e=\frac{.067 V^{2}}{R}, \text { where } V \text { is in } \mathrm{mph} \\
& \text { Let } e=0.2 g \\
& R=.335 V^{2}
\end{aligned}
$$

In other words, lateral forces can be developed between the road and a rolling tire only when the tire operates at some slip angle. The slip angle is generated as the driver turns the front wheels, and the assumption of Dr. Bross is that he makes his usual motions. Dr. Bross is right in stating that the response at $80 \mathrm{mph}$ will be different from that at $40 \mathrm{mph}$, but the car is less sensitive and, at the level assumed, the curvature of its path is only one-fourth that at $40 \mathrm{mph}$.

The second wrong premise is that the standard understeering car changes its handling characteristics in the direction of oversteer at some critical value of speed or radial force; "standard" is used because American cars with conventional suspensions are understeering. $\mathrm{He}$ refers to a paper by Janeway ( $y)$ at this point despite the fact that Janeway states quite clearly in the paper that the understeering car always has a stable static margin.

It is clear that high $\mathrm{g}$ forces do not exist under the conditions of Dr. Bross' assumption and that the normal understeering car does not reverse its steering characteristics. Therefore, it does not become unmanageable at some critical speed as Dr. Bross states. Janeway and Segel 
(8) show that an oversteering car does have a critical speed; it varies with severity of operation, that is, speed and radius of curvature, and there is no reason to believe that critical speed falls in the 65-70 mph range any more than in any other range.

In figure 2, Dr. Bross shows speed as a function of an arbitrary order of accident configuration. A curve passing through the mean speeds of the several categories is some form of exponential curve, and this is asserted to be a test of the unmanageability hypothesis. However, the choice of the order and the quantitative values assigned to the accident types by the spacing are not explained. One could rearrange the order and spacing and say the distribution was normal about the rollover type. Dr. Bross assumes that the accident category "rollover without impact with object," which occurs in the upper part of the speed range, is characterized by a high degree of unmanageability. He also asserts that unmanageability is not an important characteristic of accidents occurring at lower speeds in the categories "headon collisions," "rollover with impact with object," "collision with object," and "broadside collisions."

We concede freely that a car which has rolled over without impact with an object can be considered to have been unmanageable. We assert that a car which has collided headon with another car, or has rolled over after impact, or has collided with some object, or has struck another car broadside was also unmanageable. To assume that a driver whose car rolls over on a fill slope has lost control while a driver whose car runs into another car headon is in complete command of the situation seems to us to be drawing an unusual and rather sharp distinction.

The sparseness of two-vehicle collisions in the upper speed range suggests that drivers have sufficient control to avoid collisions at the higher speeds, even if this maneuver forces some of them into a rollover off the road.

That most rollover accidents occurring on the roadside are associated with speeds in the upper part of the range should be expected. It is almost impossible to roll a car over at low speed while, on most of our roadsides, it appears to be relatively easy to roll over at moderate speeds.
Multitudes of drivers operate very successfully in the 60-70 mph speed range on the rural freeways, turnpikes, and toll roads. On such roads, the fatality rate is approximately onehalf that of the highway system as a whole (2.4 and 5.2 fatalities per 100 million miles respectively). This indicates generally that cars don't become unmanageable in the 60-70 mph speed range and that there are more fruitful areas for research than the one suggested by Dr. Bross.

We have suggested elsewhere (9-11) that the most effective solution to the problem is a comprehensive improvement of the roadside by elimination of the obstacles, including opposing traffic, and modification of the slope and ditch sections so that they are readily traversable for a distance of at least 33 feet from the edge of the shoulder (12).

The cost of eliminating roadside obstacles from the major test roads on the General Motors proving ground ranged from $\$ 30,000$ to $\$ 40,000$ per mile (9-11). A cost estimate on a short section of hilly terrain showed $\$ 26,000$ per mile more for "ideal" construction than for construction according to 1926 standards. A test loop constructed in 1950 cost about $\$ 9,500$ more per mile than if conventional highway standards had been used. In comparison, Twombly shows that the average annual accident cost in Massachusetts on a road with no control of access and carrying average daily traffic of 15,000 vehicles is approximately $\$ 40,000$ per mile (13). Thus there seems to be reasonably close correspondence between the annual cost of accidents on such a road and the cost of eliminating roadside obstacles.

We conclude that the premises upon which Dr. Bross' hypothesis is based are erroneous, and that verification rests on extremely unusual distinctions among accident types. We concede that there is an upper limit to the reasonable and prudent speed of operation by average drivers on every portion of street and road. We do not know how to determine this limitwe do not even know what an average driver is-but we are convinced that the limit is determined almost entirely by the character of the road, surface conditions, alignment, lane width, sight distance, traffic conditions, and the width and characteristics of the roadside, including obstacles. 


\section{REFERENCES}

(1) Evans, R. D.: Properties of tires affecting riding, steering, and handling. Journal SAE, vol. 36, No. $2,1935$.

(2) Fox, M. L.: Relation between curvature and speed. In Proceedings of the 17th Annual Meeting, Highway Research Board, Washington, D.C., 1937.

(3) Bull, A. W.: Tire behavior in steering. Journal SAE, vol. 45, No. 2, 1939.

(4) Stonex, K. A.: Car control factors and their measurement. SAE Transactions, vol. 48, No. 3, 1941.

(5) Stonex, K. A.: Passenger car wind and rolling resistance. SAE Paper No. 317, March 1949.

(6) Stonex, K. A. : Automotive test track design. In Proceedings of the Highway Research Board. Bulletin 149, 1956.

(y) Janeway, R. N.: Vehicle design aspects of safe handling. In Proceedings of the conference on passenger car design and highway safety. Association for the Aid of Crippled Children and Consumers Union, Mount Vernon, N.Y., 1962, pp. 25-57.

(8) Segel, L.: Theoretical prediction and experimental substantiation of the response of the automobile to steering control. In Proceedings of the Automobile Division, Institution of Mechanical Engineers, No. 7, 1956-57.

(9) Lundstrom, L. C.: Safety aspects of vehicle-road relationships. SAE Summer Session, 1958.

(10) Stonex, K. A.: Roadside design for safety. In Proceedings of the Highway Research Board, vol. 39 (1960).

(11) Cichowski, W. G., Skeels, P. C., and Hawkings, W. R.: Guardrail installations-appraisal by proving ground car impact and laboratory tests. In Proceedings of the Highway Research Board, vol. 40, 1961.

(12) Stonex, K. A., and Skeels, P. C. : Development of crash research techniques at the General Motors proving ground. In Proceedings of the $42 \mathrm{~d}$ annual meeting of the Highway Research Board, 1963. To be published.

(13) Twombly, B. B. : Economic costs of traffic accidents in relation to highway systems. Public Roads, vol. 31, No. 2, June 1960.

\section{REPLY}

Irwin D. J. Bross, Ph.D., director of biostatistics, Roswell Park Memorial Institute, Buffalo, N.Y.

EVER since the days when an English law required that motor vehicles be preceded by a man with a warning flag, the automobile industry has fought all proposals to curtail top speeds. By now, rejection and disparagement of suggestions for speed limitation is a matter of automatic reflex rather than careful reflection. I hope you will publish the letter from Mr. Stonex (and this reply) in the hope of stimulating automobile engineers to an "agonizing reappraisal" of their views on speed.

In my article, "Highway Risks at Extreme Speed," I presented some salient facts. One of these was: Although only a small proportion of cars travel at extreme speeds (over $70 \mathrm{mph}$ ), these cars account for half of all the fatalities in rural highway accidents. To explain the fact that there is a sharp increase in risk when cars travel at speeds over $70 \mathrm{mph}$, I offered an "unmanageability" hypothesis (based on recent advances in engineering theory by Segel, Janeway, and others).

Mr. Stonex states in his communication, "Multitudes of drivers operate very successfully in the 60-70 mph speed range on the rural freeways, turnpikes, and toll roads. On such roads, the fatality rate is approximately onehalf that of the highway system as a whole (2.4 and 5.2 fatalities per 100 million miles respectively). This indicates generally that cars don't become unmanageable in the $60-70 \mathrm{mph}$ speed range and that there are more fruitful areas for research than the one suggested by Dr. Bross." But, as I repeatedly stated in my article, I was talking about speeds over $70 \mathrm{mph}$, which is what I called "extreme speed."

Since the question of turnpike fatalities has come up, I might mention corroborative evidence for which I am indebted to Mr. Wakeland. The data consist of fatality rates per 100 million vehicle-miles averaged over the 3-year period 1958-60. As Mr. Stonex mentions, on most turnpikes speeds over $70 \mathrm{mph}$ are illegal. But on two highway systems extreme speeds are legal. One of these, in Kansas, has a 6.0 fatality rate and the other, in Oklahoma, has a rate of 6.5. Although comparison between rates on different roads is tricky, the two fatality rates mentioned stand out like a sore thumb. For 15 other road systems the average rate is 2.5 , with the rates ranging from a low of 0.7 to a high of 3.9 .

Mr. Stonex also objects to "two premises which cannot be sustained." I agree. The premises are absurd. But they are not mine. He says: "By this we conclude that Dr. Bross means that the driver turns the steering wheel 